\title{
JÚRIS COMPOSTOS POR SEIS PESSOAS PARA JULGAMENTOS DE CRIMES GRAVES SÃO CONSTITUCIONALMENTE ADMISSÍVEIS?*
}

DAVID S. KEMP ${ }^{\dagger}$

Nos Estados Unidos, as pessoas reagiram amplamente ao veredicto de absolvição por assassinato de George Zimmerman. ${ }^{\mathrm{NT}}$ Em vez de reiterar o que já foi dito sobre o mérito do caso, a correção da sentença ou os maiores problemas das relações raciais nos Estados Unidos, aproveitarei a oportunidade para discutir o papel do júri em casos criminais.

Notavelmente, o júri no julgamento de Zimmerman era composto por seis pessoas, de acordo com a lei da Flórida. Os seis jurados concluíram, por unanimidade, que Zimmerman não era culpado pelo crime de assassinato em segundo grau e homicídio culposo. Neste artigo, vou avaliar se o júri composto por seis pessoas é constitucionalmente suficiente em casos criminais como este.

Discutirei, de início, a importância histórica e o papel do júri, em especial nos julgamentos criminais. Então, descreverei os casos em que a Suprema Corte dos Estados Unidos admitiu algumas variações na exigência tradicional de votações unânimes por júris compostos por doze

\footnotetext{
* Texto original publicado pelo Justia, em 19 de julho de 2013: $<$ https://verdict.justia.com/2013/07/19/a-case-against-the-six-person-jury-for-seriouscrimes $>$. Tradução e revisão de Antonio Sepulveda, Professor da Universidade Federal Fluminense (UFF), Rio de Janeiro, Brasil, Doutorando em Direito pela Universidade Estadual do Rio de Janeiro (UERJ), Rio de Janeiro, Brasil, e Pesquisador pelo Laboratório de Estudos Teóricos e Analíticos sobre o Comportamento Institucional (LETACI/UFRJ), e Igor de Lazari, Mestrando em Direito pela Universidade Federal do Rio de Janeiro (UFRJ), Rio de Janeiro, Brasil, e Pesquisador pelo Laboratório de Estudos Teóricos e Analíticos sobre o Comportamento Institucional (LETACI/UFRJ). A tradução foi realizada de acordo com autorização autoral, formalizada em 27 de junho de 2016.

† David S. Kemp é advogado, escritor e Editor do Justia. É J.D. pela Faculdade de Direito da University of California, em Berkeley (Boalt Hall).

NT Zimmerman foi acusado pelo Estado da Florida pelo assassinato de segundo grau de Trayvon Martin. Em 2013, um júri integrado por seis membros inocentou-o por unanimidade.
} 
pessoas. À luz destes casos e da lógica da Corte usada para tomar suas decisões, concluirei que o júri composto por seis pessoas nos crimes puníveis com prisão perpétua aparentemente viola a Constituição, e que a Suprema Corte deveria rever a sua jurisprudência.

\section{O PAPEL DO JÚRI EM JULGAMENTOS CRIMINAIS}

Júris têm desempenhado um papel central em julgamentos, pelo menos desde o século XIII, e foram solidamente parte do sistema inglês no momento da fundação dos Estados Unidos. Baseando-se nesta rica história, o artigo III da Constituição dos EUA estabelece que "o julgamento de todos os crimes, exceto em casos de impeachment, será realizada por júri". A Sexta Emenda ampliou essa exigência, afirmando: "Em todos os processos criminais, os acusados gozarão do direito a um julgamento rápido e público, por um júri imparcial do Estado e do Distrito onde o crime haja sido cometido".

Por muito tempo assumiu-se que o direito de julgamento por júri significava o direito a um júri de 12 pessoas (originalmente, homens brancos). Em 1898, no caso Thompson v. Utah, a Suprema Corte declarou expressamente que "o júri referido na Constituição original e na Sexta Emenda é um júri constituído, como era na common law, de doze pessoas, nem mais nem menos".

Em 1968, o Tribunal decidiu no caso Duncan v. Louisiana que o direito previsto na Sexta Emenda a um julgamento por júri era aplicável aos Estados por força da Décima Quarta Emenda. Assim, sob Thompson e Duncan, o júri composto por doze pessoas era um requisito tanto para julgamentos criminais federais quanto estaduais.

A Corte rediscutiu a decisão em Thompson, porém, em 1970. Em Williams v. Florida, o acusado recorreu da sentença de condenação, alegando que o júri de seis pessoas que o considerou culpado o privou de seu direito constitucional a um julgamento por um júri (o que significaria, segundo a Constituição, um júri de doze pessoas). A lei da Flórida tinha sido alterada em 1967 para permitir júris de seis pessoas para todos os casos criminais, exceto aqueles relativos à pena capital, para os quais ainda se exigiam júris compostos de doze pessoas (curiosamente, a nova lei também permitiu que mulheres integrassem o júri, ao passo que, antes, apenas homens eram jurados elegíveis).

Em Williams, o Tribunal entendeu que a Constituição não impõe uma exigência quanto ao número de jurados que devem compor um júri. Apesar de chegar à conclusão oposta em Thompson, no caso Williams a Corte não encontrou "absolutamente nenhuma indicação" de que um júri 
deva ter exatamente as mesmas características que a common law inglesa impusera. Assim, sob o caso Williams, desde que o júri realize a função de "evitar a opressão por parte do Governo", um júri de menos de doze jurados é constitucionalmente admissível.

A Corte erodiu ainda mais a aderência tradicional aos júris unânimes de doze pessoas nas suas decisões de 1972, em Apodaca v. Oregon e Johnson v. Louisiana, nas quais considerou que os resultados de júri 10-2 e 9-3, respectivamente, foram constitucionalmente suficientes para condenar um réu criminal.

Os Ministros dissidentes nestas decisões paradigmáticas advertiram que a jurisprudência em desenvolvimento nesta área do Direito criou uma distinção arbitrária entre júris constitucionais e inconstitucionais: se 10-2 e 9-3 foram suficientes, então o que dizer de 8-4 ou 7-5? E se seis jurados fossem aceitáveis, o que dizer sobre cinco, ou três? Poderia um Estado permitir um veredicto de culpado por um júri não-unânime de menos de doze jurados, digamos 6-3 ou 5-1? A convicção supera uma dúvida razoável quando um ou mais jurados não possuem certeza? Estas foram todas as possibilidades que as decisões do Tribunal levantaram sem respondê-las definitivamente.

Em 1978, o Tribunal decidiu no caso Ballew v. Geórgia que uma lei da Georgia permitindo júris compostos de cinco pessoas violava o direito constitucional a um julgamento por júri. E, no ano seguinte, a Corte decidiu em Burch v. Louisiana que uma condenação penal com base em um veredicto de 5-1 era igualmente inconstitucional. Assim, o Tribunal delineou os seguintes limites: os júris devem ser compostos de seis a doze pessoas, e se o número de jurados for apenas seis, então os seis devem votar de maneira unânime. Essa jurisprudência deixou ampla zona cinzenta, no entanto.

\section{TAMANHO DO JÚRI E A GRAVIDADE DA ACUSAÇÃO}

À medida que o Tribunal desenvolvia sua nova jurisprudência sobre requisitos de tamanho júri e unanimidade, surgiu uma consideração fundamental, relativa à gravidade da acusação em questão. Apesar de outras mudanças, o Tribunal deixou intocado o princípio de que os crimes federais de menor potencial ofensivo (geralmente definidos como aqueles para os quais a pena máxima é inferior a seis meses de prisão) prescindem do julgamento por júri, a que se refere a Sexta Emenda. Em Duncan v. Louisiana, a Corte decidiu que "nos Estados americanos, como no sistema judicial federal, o julgamento por um júri para crimes graves 
é um direito fundamental, essencial para evitar erros judiciais e para garantir que julgamentos justos sejam acessíveis a todos os réus". Nesse caso, a Corte reconheceu que esta mesma limitação se aplica aos Estados por razão da Décima Quarta Emenda. Independentemente da duração da pena que se pretende aplicar ao réu, da acusação de um crime grave decorre o direito a um julgamento por júri.

A Corte em Duncan foi cuidadosa ao não definir um limite exato entre infrações que são considerados "graves" e de "pequeno potencial ofensivo", adotando a demarcação tradicional de seis meses como um mero indicador. Embora a Constituição imponha aos Estados requisitos processuais penais mínimos relativos ao devido processo legal, ela também permite aos Estados a liberdade substancial para editar suas próprias leis e ordenar suas próprias políticas públicas. De fato, em Johnson v. Louisiana, caso de 1972, confirmando um veredicto de culpado de 9-3, o Tribunal declarou que o Legislativo de cada Estado possui o poder discricionário para alterar o quórum necessário para se obter uma condenação com base na gravidade da punição e da gravidade do crime.

\section{JÚRIS DE SEIS PESSOAS SÃO INFERIORES A JÚRIS DE DOZE PESSOAS}

As razões que o Tribunal deu para chegar à sua conclusão em Williams v. Florida têm sido desde então rebatidos. Entre as razões afirmou-se que:

- Um júri de seis membros seria suficiente para promover a deliberação de grupo, para isolar membros de intimidação externa e para fornecer uma amostra representativa da comunidade.

- Não havia nenhuma evidência de que os painéis de seis membros eram menos confiáveis do que os painéis de doze membros.

- Não haveria diferenças significativas nos resultados, incluindo os júris inconclusivos (hung juries).

- Uma redução do tamanho não reduziria o caráter representativo ou a diversidade do júri.

Um estudo de 1997 publicado em Law and Human Behavior refutou cada uma dessas razões. O estudo descobriu que "os júris maiores são mais propensos do que os júris menores a conter membros de grupos minoritários, deliberar mais, e, possivelmente, lembrar dos depoimentos 
do julgamento com mais precisão". Embora outros estudos questionem os resultados e metodologias de pesquisa sobre tamanhos de júri, a maioria dos estudos publicados são consistentes com a conclusão de que júris de doze pessoas são superiores a júris de seis pessoas. A Corte em Ballew v. Geórgia avaliou muitos desses estudos antes de chegar à conclusão de que um júri de cinco pessoas viola a Sexta Emenda. Isso por si só não significa, contudo, que júris de seis pessoas para casos que envolvam infrações graves sejam constitucionalmente insuficientes.

Permitir que júris de seis pessoas condenem réus e os sentenciem a uma das mais rigorosas penas nos EUA, na melhor das hipóteses, atenderá ao comando constitucional. Embora o Estado da Florida requeira um júri de doze pessoas para impor a pena capital a um réu criminal, o terreno movediço em que a decisão do Tribunal baseou a sua decisão na Williams é ainda menos sólida agora do que era há quarenta anos quando o caso foi decidido.

Nesta era da Internet, da mídia social e da opinião pública mais robusta e participativa, é cada vez mais importante não só que os tribunais realmente realizem a justiça, mas também que aparentem fazêlo. Em julgamentos importantes como o de George Zimmerman, todos os lados do debate se beneficiariam da forte sensação de que a justiça foi feita, e um júri de doze pessoas, sem dúvida, não avança apenas na realização da justiça, mas também na percepção do público de que justiça foi feita.

Júris compostos por seis pessoas para julgamentos de crimes graves são constitucionalmente admissíveis?

A case against the six-person Jury for serious crimes Submetido em: 2016-07-01 Aceito em: 2016-07-18 